\title{
Integration of marine food chain model POSEIDON in JRODOS and testing versus Fukushima data
}

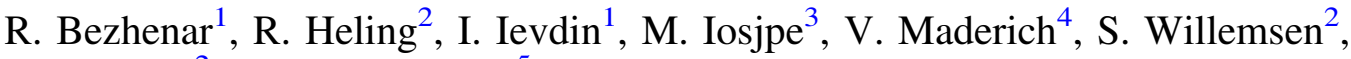 \\ G. de With ${ }^{2}$ and A. Dvorzhak ${ }^{5}$ \\ ${ }^{1}$ Ukrainian Center of Environmental and Water Projects (UCEWP), Glushkov Av., 42, Kiev 03187, Ukraine. \\ 2 NRG, Utrechtseweg 310, 6800 ES Arnhem, The Netherlands. \\ 3 Norwegian Radiation Protection Authority, P.O. Box 55, Grini naringspark 13, 1345 N-1332 Østerås, Norway. \\ ${ }^{4}$ Institute of Mathematical Machines \& Systems Problems of National Academy of Sciences of Ukraine (IMMSP), Glushkov Av., 42, \\ Kiev 03187, Ukraine. \\ ${ }^{5}$ CIEMAT, Complutense, 40, 28040 Madrid, Spain.
}

\begin{abstract}
The marine box model POSEIDON-R was integrated into the JRODOS decision support system. The POSEIDON-R dynamic food web model was extended by a benthic food chain to describe the migration of radionuclides from contaminated bottom sediments to marine organisms. The model was validated using experimental data from the Fukushima accident. Simulated concentrations of ${ }^{137} \mathrm{Cs}$ in water, bottom sediments and marine organisms are in good agreement with measurements. An example of application of JRODOS was demonstrated for Acerinox incident (Spain, 1998).
\end{abstract}

Keywords: compartment modelling / radionuclide transfer / marine organisms / food chain

\section{Introduction}

The Fukushima accident has demonstrated the importance of the marine pathways to the radiation dose for humans from the nuclear accidents and necessity of marine models integration into the decision support systems (DSSs). Within the frame of the European research project PREPARE the box model POSEIDON-R (Lepicard et al., 2004) was improved and integrated in the Hydrological Dispersion Module of the JRODOS DSS (Zheleznyak et al., 2010). The dynamic food web model in POSEIDON-R was extended by a benthic food chain to describe migration of radionuclides from contaminated bottom sediments to marine organisms. The POSEIDON-R model was linked with Atmospheric Dispersion Module (ADM) and dose module in JRODOS. The model was validated on the data from the Fukushima accident and applied to the Acerinox incident (Spain).

\section{Integration of POSEIDON model in JRODOS}

The POSEIDON-R (Lepicard et al., 2004; Maderich et al., 2014a, 2014b; Bezhenar et al., 2016) is a box model where the marine environment is modelled as a system of compartments for the water column, bottom sediment and biota. The radionuclide concentration for each compartment is governed by a set of differential equations including the temporal variations of concentration, the exchange with adjacent compartments and with the suspended and bottom sediment, radioactive sources and decay. The exchange between the water column boxes is described by fluxes of radionuclides due to advection, sediment settling and turbulent diffusion processes.

In this study, the dynamic food web model was extended to include benthic organisms. A scheme of the radionuclide transfer through the marine food web is shown in Figure 1. Model includes pelagic and benthic food chains. Pelagic organisms are grouped into phytoplankton, zooplankton, nonpiscivorous and piscivorous fishes. Benthic organisms include deposit feeding invertebrates, demersal fish and bottom predators. Deposit feeding invertebrates ingest organic parts of bottom sediments with adsorbed radionuclides which then migrate through the food chain and form an additional pathway of contamination for marine organisms. The crustaceans, molluscs and coastal predators in the model feed themselves with both pelagic and benthic organisms. The POSEIDON-R model was integrated in JRODOS linking through interface with ADM to obtain deposited activity and linking with dose module of JRODOS.

\section{Testing of simulation results versus Fukushima data}

The POSEIDON-R model was customized for the northwestern Pacific and adjacent seas (Maderich et al., 2014a, 2014b). The simulation was carried out for period 1945-2020 for ${ }^{134,137} \mathrm{Cs}$ and ${ }^{90} \mathrm{Sr}$ using data on nuclear weapon tests fallout, Chernobyl deposition, deposition and direct release, 
and continuous leak after Fukushima accident. Figure 2 shows good agreement between simulated and measured ${ }^{137} \mathrm{Cs}$ concentrations in water (Figure 2a), bottom sediments (Figure 2b) demersal fish (Figure 2c) and coastal predators (Figure 2d). The comparison in this figure comes from a coastal box with a circular-shaped surface area and a radius of $15 \mathrm{~km}$ around the Fukushima Daichi Nuclear power Plant (FDNPP). Measurements before accident were extracted from MEXT (2010) data whereas after accident TEPCO (2014) data were used for water and bottom sediments and JFRA (2015) data were used for fish. The development of a benthic food web model allows for a wider range of fish species to be considered. The geometric mean ratio for the simulated-to-observed values is in the range of $0.93-1.19$. The detailed comparisons with

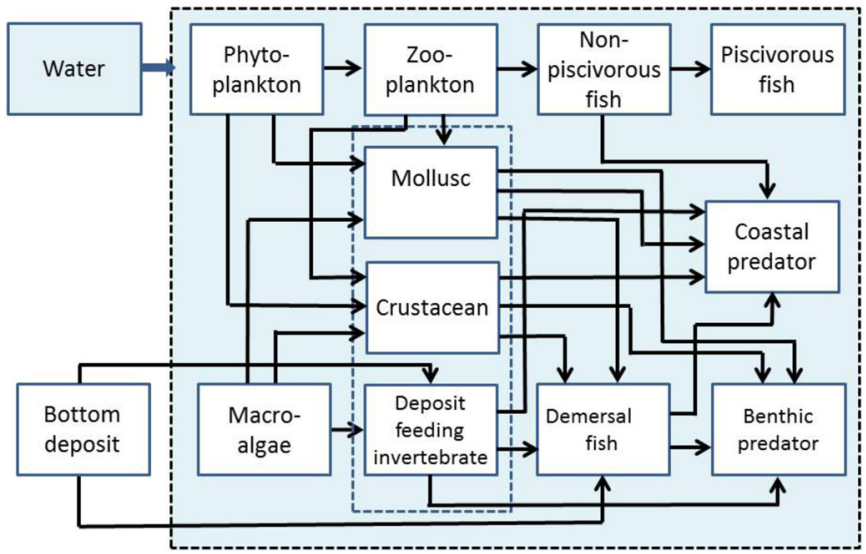

Figure 1. Scheme of radionuclide transfer to marine organisms (Bezhenar et al., 2016).
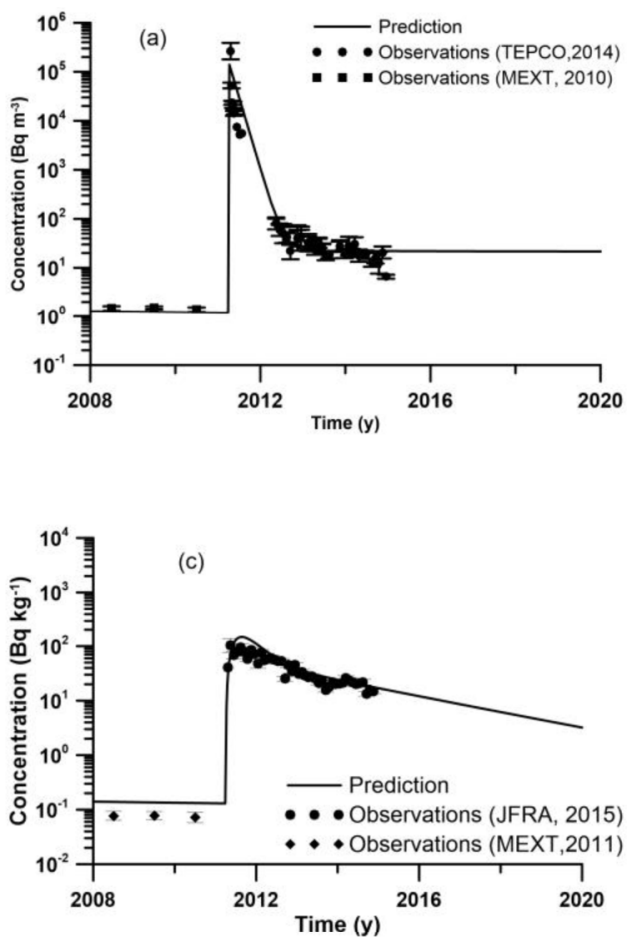

observations are given by Maderich et al. (2014a, b) and Bezhenar et al. (2016).

\section{Acerinox incident}

The dispersion of the ${ }^{137} \mathrm{Cs}$ due to the incident in steel plant belonging to the enterprise Acerinox, S.A., in the south of Spain on May 30, 1998 was simulated by JRODOS using chain of long range atmospheric transport model and POSEIDON-R model. The results of an ADM simulation, total (dry and wet) deposition on the surface of Mediterranean Sea, were used as input data for POSEIDON-R model that was customized for the Mediterranean Sea using 69 horizontal boxes divided on 3 vertical layers on depths 100 and $500 \mathrm{~m}$. The water fluxes between boxes were obtained by the averaging ocean reanalysis data for 1990-1999 (CMEMS, 2015). Figure 3 shows the distribution of ${ }^{137} \mathrm{Cs}$ in the water in June 1998 and time series of ${ }^{137} \mathrm{Cs}$ concentration in the non-piscivorous fish in the compartment near the Marseille.

\section{Conclusions}

The marine box model POSEIDON-R was integrated into the JRODOS DSS. The POSEIDON-R dynamic food web model was extended with a benthic food chain to describe migration of radionuclides from contaminated bottom sediments to marine organisms. The model was validated using data from the Fukushima accident. Simulated concentration of ${ }^{137} \mathrm{Cs}$ in the water, bottom sediments and marine organisms are in good agreement with measurements. An example of application of JRODOS was demonstrated for Acerinox incident (Spain, 1998).
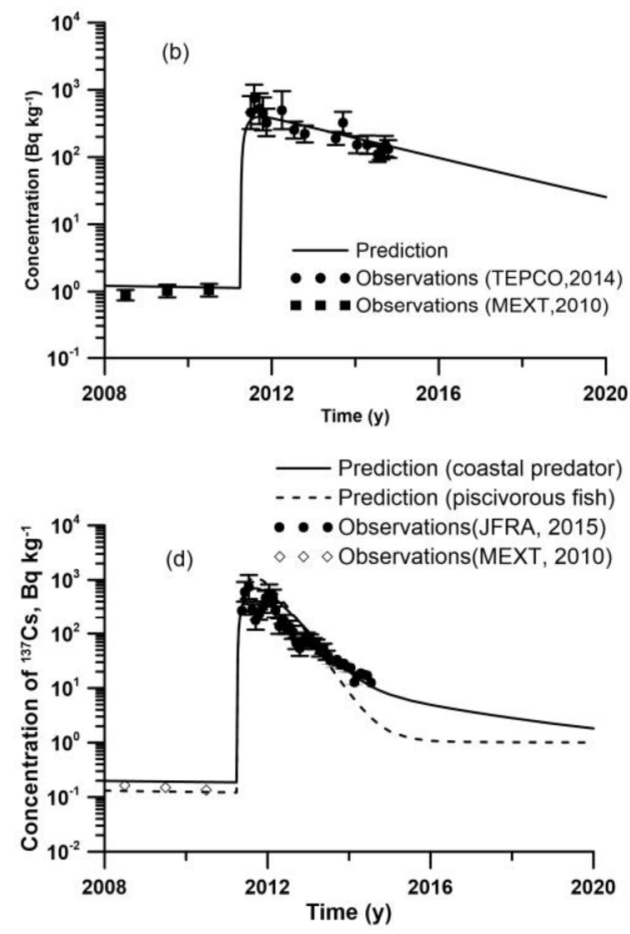

Figure 2. Comparison between simulated and measured concentration of ${ }^{137} \mathrm{Cs}$ in the water (a), bottom sediments (b), demersal fish (c) and coastal predators (d) in coastal box around FDNPP (Bezhenar et al., 2016). 


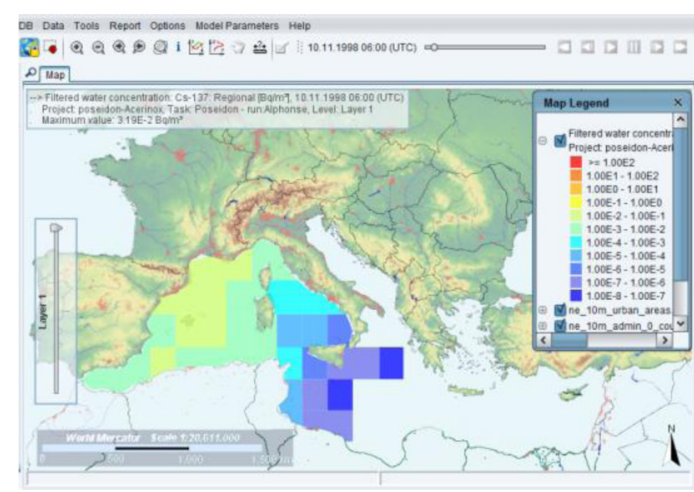

(a)

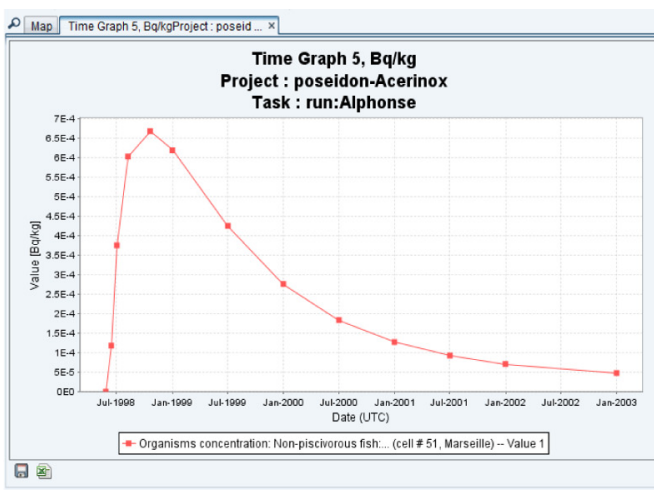

(b)

Figure 3. Distribution of ${ }^{137} \mathrm{Cs}$ in the surface water in June 1998 (a); concentration of ${ }^{137} \mathrm{Cs}$ in the non-piscivorous fish in the compartment near Marseille (b).

Acknowledgement. The research leading to these results has received funding from the European Atomic Energy Community Seventh Framework Programme FP7/2012-2013 under grant agreement 323287.

\section{References}

Bezhenar R., Jung K.T., Maderich V., de With G., Willemsen S., Qiao F. (2016) Transfer of radiocaesium from contaminated bottom sediments to marine organisms through benthic food chain in postFukushima and post-Chernobyl periods, Biogeoscience 13, 30213034.

CMEMS (Copernicus Marine Environment Monitoring Service) (2015) http://marine.copernicus.eu/web/69-interactive-catalogue.php.

JFRA (Japan Fisheries Research Agency) (2015) Results of the inspection on radioactivity materials in fisheries products. Available at: http://www.jfa.maff.go.jp/e/inspection/index.html.

Lepicard S., Heling R., Maderich V. (2004) POSEIDON-R/RODOS models for radiological assessment of marine environment after accidental releases: application to coastal areas of the Baltic, Black and North Seas, J. Environ. Radioact. 72, 153-161.
Maderich V., Bezhenar R., Heling R., de With G., Jung K.T., Myoung J.G., Cho Y.-K., Qiao F., Robertson L. (2014a) Regional longterm model of radioactivity dispersion and fate in the Northwestern Pacific and adjacent seas: application to the Fukushima Daiichi accident, J. Environ. Radioact. 131, 4-18.

Maderich V., Jung K., Bezhenar R., de With G., Qiao F., Casacuberta N., Masque P., Kim Y.H. (2014b) Dispersion and fate of ${ }^{90} \mathrm{Sr}$ in the Northwestern Pacific and adjacent seas: global fallout and the Fukushima Dai-ichi accident, Sci. Total Environ. 494-495, 261271.

MEXT (Japanese Ministry of Education, Culture, Sports, Science and Technology) (2010) Environmental radiation database. Available at: http://search.kankyo-hoshano.go.jp/servlet/search.top.

TEPCO (Tokyo Electric Power Company) (2014) Current situation of Fukushima Daiichi and Daini nuclear power station. Available at: http://www.tepco.co.jp/en/nu/fukushima-np/index-e.html.

Zheleznyak M., Potempski S., Bezhenar R., Boyko A., Ievdin I., Kadlubowski A., Trybushnyi D. (2010) Hydrological dispersion module of JRODOS: development and pilot implementation - the Vistula river basin, Radioprotection 45 (5), 113-122.

Cite this article as: R. Bezhenar, R. Heling, I. Ievdin, M. Iosjpe, V. Maderich, S. Willemsen, G. de With, A. Dvorzhak. Integration of marine food chain model POSEIDON in JRODOS and testing versus Fukushima data. Radioprotection 51(HS2), S137-S139 (2016). 